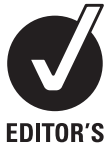

CHOICE

\title{
Tackling the wider social determinants of health and health inequalities: evidence from systematic reviews
}

\author{
C Bambra, ${ }^{1}$ M Gibson, ${ }^{2}$ A Sowden, ${ }^{3} \mathrm{~K}$ Wright, ${ }^{3} \mathrm{M}$ Whitehead, ${ }^{4} \mathrm{M}$ Petticrew ${ }^{5}$
}

\begin{abstract}
- A supplementary appendix is published online only at http:// jech.bmj.com/content/vol64/ issue4

${ }^{1}$ Department of Geography, Durham University, Durham, UK ${ }^{2}$ MRC Social and Public Health Sciences Unit, Glasgow, UK ${ }^{3}$ Centre for Reviews and Dissemination, University of York, York, UK

${ }^{4}$ Division of Public Health, University of Liverpool, Liverpool, UK

${ }^{5}$ Public and Environment Health Research Unit, London School of Hygiene and Tropical Medicine, London, UK
\end{abstract}

\section{Correspondence to}

Clare Bambra, Department of Geography, Wolfson Research Institute, Durham University Queen's Campus, Stockton on Tees TS17 6BH, UK; clare.bambra@durham.ac.uk

Accepted 3 June 2009

\section{ABSTRACT}

Background There is increasing pressure to tackle the wider social determinants of health through the implementation of appropriate interventions. However, turning these demands for better evidence about interventions around the social determinants of health into action requires identifying what we already know and highlighting areas for further development.

Methods Systematic review methodology was used to identify systematic reviews (from 2000 to 2007, developed countries only) that described the health effects of any intervention based on the wider social determinants of health: water and sanitation, agriculture and food, access to health and social care services, unemployment and welfare, working conditions, housing and living environment, education, and transport.

Results Thirty systematic reviews were identified. Generally, the effects of interventions on health inequalities were unclear. However, there is suggestive systematic review evidence that certain categories of intervention may impact positively on inequalities or on the health of specific disadvantaged groups, particularly interventions in the fields of housing and the work environment.

Conclusion Intervention studies that address inequalities in health are a priority area for future public health research.

It is well established that health follows a social gradient: better health with increasing socioeconomic position. ${ }^{1}$ The importance of the social (as opposed to biological or genetic) causes of this gradient-for example, housing quality, access to healthcare or quality of work, has also been established. ${ }^{2}{ }^{3}$ In turn, this has lead to increasing pressure in research, practice and policy-making environments to tackle these wider social determinants of health, through the implementation of appropriate interventions, and thereby reducing the gradient and health inequalities. ${ }^{2-4}$

However, there are two concurrent problems. First, the social determinants evidence base is dominated by descriptive, epidemiological studies that, by highlighting associations, are only implicitly able to suggest possible interventions. For example, studies consistently show associations between higher job control and better mental health; by implication, therefore, interventions that increase job control should result in health improvements. ${ }^{5}$ What is lacking though is further evidence about what sort of interventions might be required or whether they will actually be effective in improving health or reducing the social gradient.
Second, where interventions aimed at reducing health inequalities have been developed and evaluated, they tend to focus on modifying lifestyle factors such as smoking. This may reflect the fact that lifestyle issues are often easier to identify and treat, or it may be indicative of differences in the respective evidence bases; with evidence on tackling the wider social determinants being less apparent and less accessible to policy makers and practitioners. Therefore, what is needed is evidence about what can actually be done to tackle the social determinants of health and health inequalities-specifically which interventions are effective and for whom. ${ }^{6}$ This requires evaluative studies of interventions that address the social determinants of health. ${ }^{37}$ The WHO Measurement and Evidence Knowledge Network - for example, noted that it is vital to continue to develop evidence bases about tackling the social determinants of health and health inequalities. ${ }^{8}$

However, turning this need for better evidence about interventions around the social determinants of health into action requires the identification of what we already know in terms of the effects of interventions and also identifying areas where new studies are needed. This information could then be used to identify priorities for new research. It was in this context that the English Department of Health, Policy Research Programme, via the Public Health Research Consortium, commissioned this umbrella review. Umbrella reviews are an increasingly common way of identifying, appraising and synthesising systematic review evidence. ${ }^{9-12}$ In addition, umbrella reviews are able to present the overarching findings of such systematic reviews. ${ }^{13}$ This article therefore synthesises recent systematic reviews on the effects on health and health inequalities of interventions aimed at influencing the social determinants of health.

\section{METHODS}

Systematic review methodology was used to locate and evaluate published and unpublished systematic reviews of interventions around the wider social determinants of health ("umbrella" review).

\section{Search strategy}

Initially, the Centre for Reviews and Dissemination Wider Public Health database (a web-based database of systematic reviews of public health and related interventions) was manually searched. This consists of evidence from systematic reviews relevant to public health policy and practice and covers the period from 2000 to 2002. To supplement this, the Cochrane Database of Systematic Reviews and 
the Database of Abstracts of Reviews of Effects (both administrative and public databases) were searched electronically, whereas the Campbell Collaboration Database and the EPPI Centre database of health promotion and public health studies were manually searched from January 2002 to April 2007. Electronic searches of the Criminal Justice Abstracts database (2000-2007) were also undertaken (as it is not covered by any of these databases of systematic reviews). Bibliographies, reference lists and relevant websites were also searched. Experts were contacted and we hand searched four leading journals (American Journal of Public Health, American Journal of Preventive Medicine, Journal of Epidemiology and Community Health, Social Science and Medicine) from January 2002 to April 2007. Full search strategy is in web appendix 1.

\section{Inclusion and exclusion criteria}

We used the widely cited Dahlgren and Whitehead rainbow model of the main determinants of health (figure 1) as a framework to help to identify the range of social determinants upon which interventions could be based. ${ }^{14}$ We concentrated on the outer two layers, which included macroeconomic, cultural and environmental conditions in the outermost layer; and living and working conditions and access to essential goods and services in the next layer, specifically water and sanitation, agriculture and food, access to health (and social care) services, unemployment (and welfare), work conditions, housing (and living environment), education and transport. We therefore excluded reviews that only examined interventions based on the inner most layers of the rainbow: individual lifestyle factors and social and community networks.

Only studies of adult participants (16+) or the general population in developed countries (North America, Europe, Australasia, Japan) were eligible for inclusion. We limited our study to adults because an Institute of Education team was conducting a concurrent umbrella review of child health outcomes. ${ }^{15}$ In terms of outcomes, we were particularly interested in the impacts on inequalities in health or well-being (by socioeconomic status), although we also looked at the overall health effect. We also considered as outcomes the non-health effects (such as employment or income) on people from a disadvantaged group with a pre-existing health condition.

Systematic reviews had to meet the two mandatory criteria of Database of Abstracts of Reviews of Effects: (1) that there is a defined review question (with definition of at least two of, the interventions, participants, outcomes or study designs) and (2) that the search strategy included at last one named database, in conjunction with either reference checking, hand-searching, citation searching or contact with authors in the field.

\section{Data extraction}

Two reviewers $(\mathrm{CB} / \mathrm{MG})$ independently screened all titles and abstracts identified from the literature search for relevance $(n=1694)$. Full paper manuscripts of any titles/abstracts that were considered relevant by either reviewer were obtained $(n=84)$ and independently assessed for inclusion. Any discrepancies were resolved by consensus and, if necessary, a third reviewer (MP) was consulted. Only studies meeting all the inclusion criteria were data extracted $(n=30)$.

\section{RESULTS}

Thirty systematic reviews of interventions were identified. These are synthesised by domain type in tables $1-4$ and in the text below.

\section{Housing and living environment}

There is a "housing evidence base" that goes back many decades, including early evaluation studies from the 1930s and a number of controlled trials, and more recently several randomised controlled trials. ${ }^{16}$ Given this historical focus on the relationship between housing and health, it is probably not surprising that the systematic review housing evidence base is better developed than for other domains. We identified nine systematic reviews focussing on housing and health (table 1) ${ }^{17-24}$ two were of "social" changes (rental assistance programmes), ${ }^{17}{ }^{18}$ five were of "environmental" changes to housing (eg, changes in lighting, or physical infrastructure, to reduce risk of falls, or injury ${ }^{19-23}$ and two were of wider area-based initiatives. ${ }^{24} 25$
Figure 1 Dahlgren and Whitehead's model of the social determinants of health.

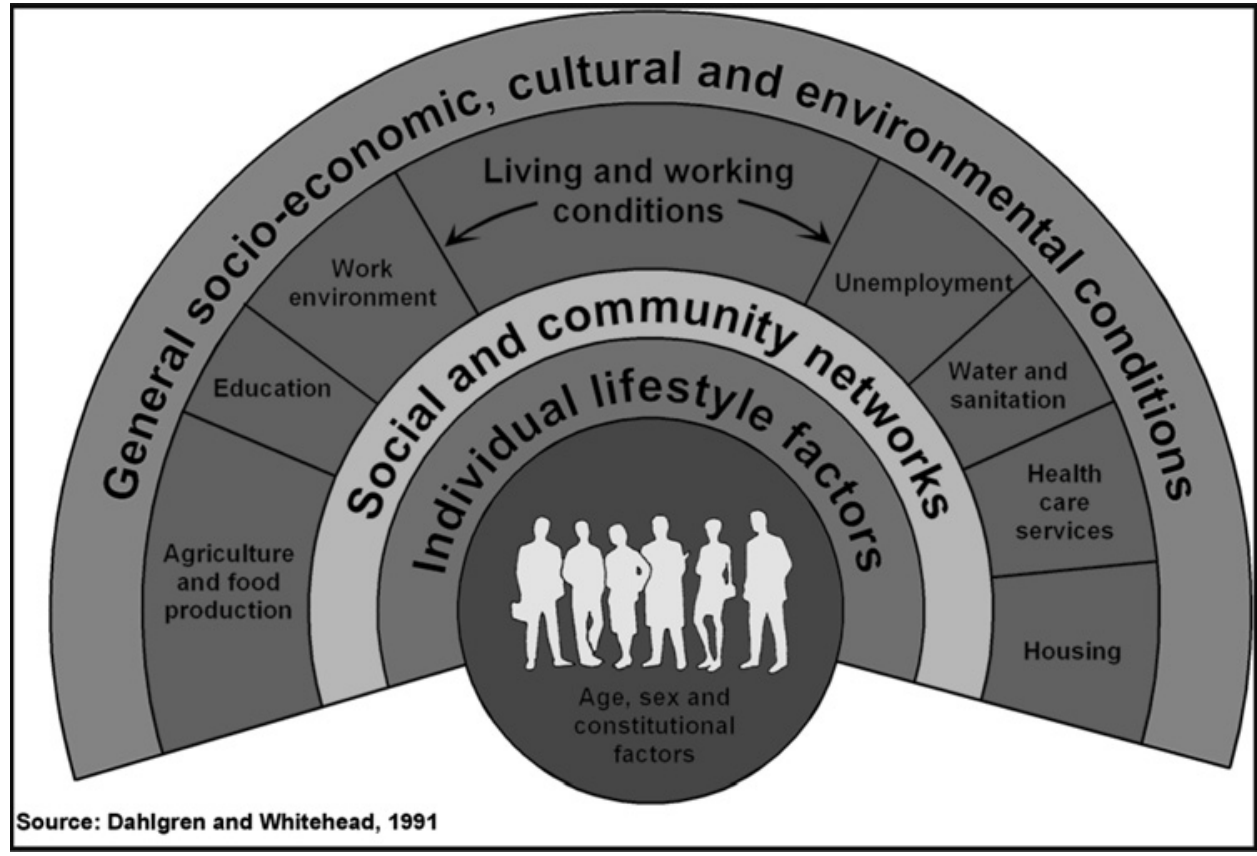


Table 1 Summary details of housing and community reviews

\begin{tabular}{|c|c|c|}
\hline Citation & Intervention(s) & Summary of results \\
\hline Anderson et $a l^{17}$ & $\begin{array}{l}\text { "Social" changes (rent assistance so that low-income families can } \\
\text { choose where to live, eg, public/private) }\end{array}$ & $\begin{array}{l}\text { Improvements in self-reported health status such as a decrease in } \\
\text { depression; improvements in social outcomes including } \\
\text { neighbourhood safety and social disorder. }\end{array}$ \\
\hline Acevedo-Garcia et al $2004^{18}$ & $\begin{array}{l}\text { "Social" changes (rent assistance so that low income families can } \\
\text { choose where to live, eg, public/private) }\end{array}$ & $\begin{array}{l}\text { Improvements reported in terms of overall health, distress and } \\
\text { anxiety, depression, problem drinking, substance abuse and } \\
\text { exposure to violence. }\end{array}$ \\
\hline Chang et al ${ }^{19}$ & $\begin{array}{l}\text { "Environmental" changes (changes in the housing infrastructure to } \\
\text { reduce risk of falls) }\end{array}$ & $\begin{array}{l}\text { NS reduction in "at least one fall" (adjusted risk ratio of } 0.900 .77 \text { to } \\
1.05 \text { ). NS reduction in monthly rate of falling (adjusted incidence } \\
\text { rate ratio } 0.850 .65 \text { to 1.11). }\end{array}$ \\
\hline McClure et $a l^{20}$ & $\begin{array}{l}\text { "Environmental" changes (changes in the housing infrastructure to } \\
\text { reduce risk of falls) }\end{array}$ & $\begin{array}{l}\text { Significant decreases in some types of fall-related injuries (relative } \\
\text { reduction in fall related injuries ranging from } 6 \% \text { to } 33 \% \text { ). }\end{array}$ \\
\hline Nilsen $^{21}$ & $\begin{array}{l}\text { "Environmental" changes (changes in the housing infrastructure to } \\
\text { reduce injuries) }\end{array}$ & $\begin{array}{l}\text { Two studies reported decreases in certain injuries but most of the } \\
\text { studies found no decline in rates of any kind of injury. }\end{array}$ \\
\hline Thomson et $a l^{22}$ & “Environmental" changes (rehousing, renovation, updating) & $\begin{array}{l}\text { Mixed effects on self-reported mental and/or physical health with } \\
\text { some studies reporting small improvements and others small } \\
\text { negative effects. Improvements found in social outcomes such as } \\
\text { perceptions of crime. }\end{array}$ \\
\hline Saegert et $a l^{23}$ & "Environmental" changes (rehousing, renovation, updating) & 49/72 studies reported a significant improvement in health. \\
\hline Thomson et $a l^{25}$ & Area-based urban regeneration & $\begin{array}{l}\text { Impact of interventions was highly variable with some studies } \\
\text { reporting improvements (in mortality), whereas others found } \\
\text { deteriorations (in self-reported health). }\end{array}$ \\
\hline Hahn et $a l^{24}$ & Area-based firearms restrictions & $\begin{array}{l}\text { Findings were inconsistent with some studies reporting reductions } \\
\text { in homicides and suicides, whereas others reported increases. }\end{array}$ \\
\hline
\end{tabular}

NS, non-significant.

Reviews of rental assistance (eg, use of rent subsidies to create mixed-income or desegregated housing in poorer US neighbourhoods) suggested that interventions to promote mixed housing may result in increases in perceived neighbourhood safety, perhaps because exposure to crimes against person and property is reduced, along with neighbourhood social disorder. There is tentative systematic review evidence that such housing mobility policies (at least in the USA) do improve health and health behaviours, but the effects are small. Research on the mechanisms is lacking and therefore required. General housing improvement is also associated with positive change in social outcomes, including reductions in fear of crime and improvements in social participation. These interventions ranged from home visits, risk assessments and removal of hazards to reduce the risk of injury, to physical changes to housing structure such as insulation, furniture and more general housing policies.
Although two reviews considered the effects on inequalities, ${ }^{22} 25$ none of the primary studies differentiated their results by socioeconomic status.

\section{Work environment}

There has been a recent shift in focus, from work as a source of occupational diseases to the wider impacts of work on health and well-being. ${ }^{5}$ This is reflected in the seven systematic reviews we located. ${ }^{26-32}$ They focussed on four types of intervention (table 2): increased employee control (via participatory "health circle" staff meetings to discuss ways to improve the work environment, more generic staff participation at work or task restructuring), ${ }^{26-28}$ changing the organisation of shift work (less nights, shorter shift lengths, etc, or the compressed working week), ${ }^{29}{ }^{30}$ privatisation $^{31}$ and the health and safety regulations. ${ }^{32}$

Table 2 Summary details of work environment reviews

\begin{tabular}{|c|c|c|}
\hline Citation & Intervention(s) & Summary of results \\
\hline Aust and Ducki ${ }^{26}$ & $\begin{array}{l}\text { Dusseldorf health circles-staff discussion groups on improving } \\
\text { working conditions }\end{array}$ & $\begin{array}{l}\text { Mixed results: sickness absence increased in the controlled study, } \\
\text { whereas it decreased in the four uncontrolled studies. One study } \\
\text { reported improvements in some psychosocial outcomes such as } \\
\text { relationships with colleagues. }\end{array}$ \\
\hline Egan et $a l^{27}$ & $\begin{array}{l}\text { Organisational-level work reorganisation: participatory committees, } \\
\text { control over hours of work }\end{array}$ & $\begin{array}{l}\text { Participatory committee interventions that increased employee } \\
\text { control had a consistent and positive impact on self-reported } \\
\text { health. }\end{array}$ \\
\hline Bambra et $a l^{28}$ & $\begin{array}{l}\text { Task structure work reorganisation: task variety, team working, } \\
\text { autonomous groups }\end{array}$ & $\begin{array}{l}\text { Task structure interventions did not generally alter levels of } \\
\text { employee control. However, where job control decreased (and } \\
\text { psychosocial demands increased), self-reported mental (and } \\
\text { sometimes physical) health appeared to get worse. }\end{array}$ \\
\hline Bambra et $a l^{29}$ & $\begin{array}{l}\text { Changing from an 8-h, 5-day week to a compressed working week } \\
\text { of a } 12 \mathrm{~h} / 10 \mathrm{~h}, 4 \text {-day week. }\end{array}$ & $\begin{array}{l}\text { Health effects were inconclusive, although there was seldom } \\
\text { a detrimental effect. Work-life balance was often improved. }\end{array}$ \\
\hline Bambra et $a l^{30}$ & Changes to the organization of shift work schedules & $\begin{array}{l}\text { Switching from slow to fast shift rotation; changing from backward } \\
\text { to forward shift rotation; and the self-scheduling of shifts were } \\
\text { found to benefit health and work-life balance. }\end{array}$ \\
\hline Egan et $a l^{31}$ & Privatisation of public utilities and industries & $\begin{array}{l}\text { Higher-quality studies suggested that job insecurity and } \\
\text { unemployment resulting from privatisation impacted adversely on } \\
\text { mental health and on some physical health outcomes. }\end{array}$ \\
\hline Rivara and Thompson ${ }^{32}$ & $\begin{array}{l}\text { Legal regulations (increased safety regulations) to prevent falls } \\
\text { from height in construction industry }\end{array}$ & $\begin{array}{l}\text { Increased regulation, when enforced with inspections, might be } \\
\text { associated with a decrease in fall injury rates. }\end{array}$ \\
\hline
\end{tabular}


Table 3 Summary details of transport and access to health and social care services reviews

\begin{tabular}{|c|c|c|}
\hline Citation & Intervention(s) & Summary of results \\
\hline \multicolumn{3}{|l|}{ Transport } \\
\hline Bunn et $a l^{35}$ & $\begin{array}{l}\text { Area-wide traffic calming schemes (creation of one ways, speed } \\
\text { humps, etc) }\end{array}$ & $\begin{array}{l}\text { Intervention has potential to reduce traffic injuries and deaths: road } \\
\text { user deaths (pooled RR } 0.63,0.14 \text { to } 2.59 \text { ) and injuries (pooled RR } \\
0.89,0.8 \text { to } 1.00 \text { ) decreased. }\end{array}$ \\
\hline Egan et $a l^{36}$ & $\begin{array}{l}\text { New road building (major urban roads, bypasses, major connecting } \\
\text { roads) }\end{array}$ & $\begin{array}{l}\text { Little evidence that major new urban roads reduce injury incidence. } \\
\text { Bypasses do appear to reduce injury accidents on main routes, but } \\
\text { this may be achieved at the cost of displacing accidents to } \\
\text { secondary routes. }\end{array}$ \\
\hline Ogilvie et $a /^{34}$ & $\begin{array}{l}\text { Population-level interventions to promote shift from using cars to } \\
\text { walking and cycling (engineering measures; financial incentives; } \\
\text { providing alternative services) }\end{array}$ & $\begin{array}{l}\text { Mixed evidence of effects of engineering interventions but financial } \\
\text { incentives and providing alternative services had some success in } \\
\text { changing journey type. Absence of evidence rather than evidence of } \\
\text { no effect. }\end{array}$ \\
\hline Shults et $a l^{33}$ & MLDA laws and BAC laws & $\begin{array}{l}\text { Decreasing the MLDA increased road injuries (effect range }-2 \% \text { to } \\
38 \% \text { ), whereas increasing the MLDA decreased road injuries (effect } \\
\text { range }-33 \% \text { to }-6 \% \text { ). Decreased BAC led to decreases in vehicle } \\
\text { crashes. }\end{array}$ \\
\hline Pilkington and Kinra ${ }^{37}$ & Fixed or mobile speed cameras & $\begin{array}{l}\text { All studies reported a reduction in road traffic collisions and } \\
\text { casualties, with the reduction in the vicinity of the camera ranging } \\
\text { from } 5 \% \text { to } 69 \% \text { for collisions, } 12 \text { to } 65 \% \text { for injuries and } 17 \% \text { to } \\
71 \% \text { for deaths. }\end{array}$ \\
\hline \multicolumn{3}{|c|}{ Access to health and social care services } \\
\hline Anderson et $a l^{38}$ & $\begin{array}{l}\text { Cultural access-“culturally competent healthcare" (language and } \\
\text { culture training for health professionals, use of interpreters, etc) }\end{array}$ & $\begin{array}{l}\text { No evidence on health outcomes found, however, healthcare use } \\
\text { and access increased. }\end{array}$ \\
\hline Lewin et $a l^{39}$ & $\begin{array}{l}\text { Cultural access - lay health worker interventions (intended to } \\
\text { promote health, manage illness or support people) delivered in } \\
\text { primary and community healthcare settings }\end{array}$ & $\begin{array}{l}\text { In comparison with usual care, promising benefits were shown for } \\
\text { promoting the uptake of immunisation in both children and adults } \\
\text { (pooled estimate RR } 1.30,1.14: 1.48 \text { ). May also be effective in } \\
\text { promoting the uptake of breastfeeding (pooled estimate } R R=1.05 \text {, } \\
\text { Cl } 0.99 \text { to } 1.12 \text { ). }\end{array}$ \\
\hline Pignone et $a l^{40}$ & $\begin{array}{l}\text { Cultural access - health education materials for patients with low } \\
\text { literacy }\end{array}$ & $\begin{array}{l}\text { Mixed effects on health, difficult to draw conclusions due to } \\
\text { diversity of outcomes, interventions and quality of studies. }\end{array}$ \\
\hline Gruen et $a l^{41}$ & $\begin{array}{l}\text { Improving geographic access - specialist outreach clinics in } \\
\text { primary care or rural hospital settings }\end{array}$ & $\begin{array}{l}\text { Specialist outreach appears to improve access to primary care and } \\
\text { self-reported health (eg, a decrease in disease symptoms in the } \\
\text { intervention group (pooled RR } 0.63, \mathrm{Cl} 0.52 \text { to } 0.77) \text { ). }\end{array}$ \\
\hline
\end{tabular}

BAC, blood alcohol concentration; MLDA, minimum legal drinking age.

Overall, interventions to improve employee control (three reviews) ${ }^{26-28}$ found consistently positive health effects when job control was actually increased ${ }^{27}$ (and negative effects when job control decreased). ${ }^{28}$ The two reviews of changes to shift work $^{29} 30$ identified some interventions (such as increased control over shift times) that had positive impacts on selfreported (particularly mental) health. ${ }^{30}$ Conversely, the privatisation review suggested that job insecurity and unemployment resulting from privatisation impacted adversely on mental health. ${ }^{31}$ The single review of increased health and safety legislation in the construction industry found a decrease in fallrelated injuries after the intervention. ${ }^{32}$

Five of the reviews explicitly looked for evidence of effects on health inequalities and three included studies that reported differences by socioeconomic status (occupation). ${ }^{27} 2831$ In one review of participatory interventions, ${ }^{27}$ one uncontrolled study found improvements in terms of mental health outcomes among manual workers but not managers or clerical employees. In

Table 4 Summary details of unemployment and welfare, agriculture and food, and water and sanitation reviews

\begin{tabular}{|c|c|c|}
\hline Citation & Intervention(s) & Summary of results \\
\hline
\end{tabular}

Unemployment and welfare

Adams et $a l^{45}$

Professional welfare rights advice in healthcare settings (welfare benefit maximisation)

Crowther et $a l^{43}$

Supported employment or prevocational training to help people with severe mental illness get into employment

Bambra et $a l^{44}$

Welfare to work interventions aimed at people out of work due to a health condition or disability

Agriculture and food Wall $^{47}$

Monetary incentives, including price decreases on low-fat snacks in vending machines, farmers' market coupons for fruit and vegetables, free food provision.

Water and sanitation Demos et al ${ }^{48}$
Changes in water fluoridation levels (typical levels were 0.05 to $1.5 \mathrm{ppm})$
Little evidence that the advice leads to measurable health and social benefits, although some studies reported improvements in self-reported mental health. Absence of evidence rather than evidence of no effect.

No significant impact on employment outcomes in comparison to standard care. Some evidence that supported employment more effective than prevocational training.

Evidence of positive employment outcomes was not compelling because, although positive outcomes ranged from $11 \%$ to $50 \%$, controls were rarely used, so there is possible confounding effect by relatively buoyant labour market.

Positive effect $s$ were found on weight loss, consumption of fruit and vegetables, redemption of coupons and attitudes towards fruit and vegetable consumption.

Fluoridation at levels up to $1 \mathrm{ppm}$ has no adverse effects on bone fracture incidence, bone mineral density or bone strength. 
another review of task restructuring, ${ }^{28}$ an uncontrolled study found that the adverse health effects of a team working intervention were only experienced by the lowest grade of employees. The review of privatisation also identified one study that found that 8 months after privatisation, occupational stress increased only among clerical and administrative staff, and not among manual workers or managers. ${ }^{31}$

\section{Transport}

Transport policies are often cited as a major influence on health and health inequalities, although it is a field where relatively few evaluative studies and reviews have been carried out (at least, ones measuring health outcomes). We located five reviews addressing transport issues (table 3). ${ }^{33-37}$ Each dealt with a different type of intervention: promoting modal shift from driving to walking and cycling; impacts of new roads; reductions in permissible alcohol when driving, area-wide traffic calming and speed cameras. Despite the differences in intervention type, four of the five reviews included outcomes related to road injuries. $^{33}$ 35-37

In relation to road injury outcomes, the review of legislative interventions to curb alcohol-impaired driving ${ }^{33}$ found strong evidence to support the reduction of fatal and non-fatal crashes, as did the reviews of traffic calming interventions ${ }^{35}$ and speed cameras. ${ }^{37}$ Evidence for the impact of new of road building on injuries $^{36}$ was less conclusive because whereas out-of-town bypasses delivered reductions in injuries, major new roads did not. There was very limited evidence available on the health effects of interventions aiming to encourage modal transport shift from driving to walking and cycling. ${ }^{34}$ None of the reviews presented any information relating to impacts on health inequalities.

\section{Health and social care services}

Access to effective healthcare is another determinant of population health. Several different types of access are relevant to the wider social determinants of health, particularly geographic, economic and cultural access. We identified four reviews in the Organisation for Economic Co-operation and Development (OECD) countries (table 3), three of which focused on interventions to improve cultural access (acceptability and appropriateness of services) ${ }^{38-40}$ and one ${ }^{41}$ on improving geographic access (location and physical availability of health services) in rural areas. No reviews of economic access (affordability of services) were identified relating to high-income countries.

Overall, the evidence evaluating interventions to promote culturally relevant healthcare was generally inconclusive. For example, although positive effects were found for lay health workers in promoting immunisation uptake, there was insufficient evidence to support the use of lay health workers in other contexts. ${ }^{39}$ Rural outreach interventions improved geographic access to care and self-reported health. ${ }^{41}$ The reviews all focused on interventions intended to improve access for disadvantaged groups (low-income and minority populations) and there was some evidence that the interventions were effective-for example, ethnic minority patient satisfaction with healthcare services increased after the cultural training intervention. ${ }^{38}$ However, none of the reviews reported whether impacts of interventions differed for different groups in the population studied.

\section{Unemployment and welfare}

There is considerable observational evidence on the linkages between unemployment and health, which suggests that ill health can be both a cause and a consequence of unemployment (the latter being the so-called direct health selection hypothesis). ${ }^{42}$ Two of the three reviews we located in this domain were of interventions that aimed to assist those who were prevented from entering the labour market by ill health-for example, through supported employment, providing skills and training, and other mechanisms. ${ }^{43} 44$ The other review evaluated interventions to increase the uptake of welfare entitlements. ${ }^{45}$ Details of the reviews are presented in table 4.

One review found that although supported employment delivered more positive employment outcomes than prevocational training, there was no significant improvement in comparison with standard care. ${ }^{43}$ Furthermore, there was little evidence of any impact on health. Similarly, the review ${ }^{44}$ of welfare to work found some evidence of positive employment effects, although it was not clear to what extent this was due to the influence of contextual confounding factors. This review contained no information on health outcomes. The review of welfare rights interventions ${ }^{45}$ indicated that there were clear financial effects with a mean gain in income of $£ 1026$ per client in the year after the intervention (2004). However, the effects on health outcomes were limited to short-term improvements in mental health. None of the reviews specifically examined differential impacts across socioeconomic groups, although importantly all interventions were targeted at disadvantaged groups.

\section{Agriculture and food}

Agricultural policies affect the quality, quantity, price and availability of food, all of which are important for public health. ${ }^{46}$ Whereas overall increases in life expectancy may be partly attributed to better nutrition, increases in the prevalence of obesity in many countries point to the contribution food policies also make to overnutrition. Agriculture and food policies and interventions may therefore provide some of the mechanisms for addressing diet-related health inequalities. However, only one review was identified (table 4). ${ }^{47}$ This focussed on monetary incentives (including price decreases) on low-fat snacks, coupons for farmers' markets, financial rewards and free food provision. All four RCTs included in the review found a positive effect of incentives on the outcomes measured: weight loss, consumption of fruit and vegetables, redemption of coupons and attitudes towards fruit and vegetable consumption. None of the studies differentiated their results by socioeconomic position and none of the reviews focussed on disadvantaged groups.

\section{Water and sanitation}

There are many aspects of water and sanitation likely to impact on population health. Aside from the direct effects of pollution and contamination, other aspects of water management, including abstraction, water metering and the provision of flood defences, may all have potential public health implications. However, there are few available systematic reviews reporting health outcomes and only one that met our inclusion criteria (table 4). ${ }^{48}$ It focussed on changes in levels of water fluoridation and did not report on the effects on health inequalities. The authors concluded that fluoridation at levels up to $1 \mathrm{ppm}$ had no adverse effects on bone fracture incidence, bone mineral density or bone strength in developed countries.

\section{Education}

There is undoubtedly a strong case for highlighting education as a major determinant of health and health inequalities - not least though its interaction with other determinants. For example, 
"Education has traditionally been an important route out of poverty for disadvantaged groups in many countries. Generally, qualifications improve people's chances of getting a job and of having better pay prospects and the resulting increase in standard of living. This in turn improves opportunities to obtain the prerequisites for health-nutritious food, safe housing, a good working environment and social participation." ${ }^{14}$ However, perhaps surprisingly, we found no systematic reviews of the health effects of adult education interventions in OECD countries published in the current decade. It should be noted that person-based health education interventions aimed at social determinants in the two inner most layers of the "rainbow" were excluded from this review.

\section{DISCUSSION}

This project aimed to identify the "state of the systematic review evidence base" in the current decade in developed countries, addressing the effects on health and health inequalities of interventions targeting the social determinants of health, as well as identifying fruitful areas for future research. The study therefore does what it aims to do, but this is of necessity a very limited answer to the problem of what works in terms of tackling health inequalities as, disappointingly, very few relevant reviews have been conducted. It has already been demonstrated elsewhere that the public health evidence base is sparsely populated, ${ }^{49}$ and this is particularly true in terms of evaluations of interventions addressing the social determinants of health, especially in relation to health inequalities. Evidence on the differential impacts of interventions by socioeconomic position is largely absent (only 3 of 30 reviews presented results for specified population subgroups), although this is likely to reflect the state of the primary study evidence base rather than that of the systematic reviews. ${ }^{22} 25293034$ What we do have however is suggestive evidence that certain categories of intervention may impact positively on inequalities or on the health of specific disadvantaged groups, particularly interventions in the fields of housing and the work environment.

In the reviews of work environment interventions-for example (such as changes to the organisation of work and privatisation), there is evidence that the effects of change are experienced differently by different levels of employee and that health outcomes differed accordingly. This suggests-as noted by Marmot and others ${ }^{50}$ - that the workplace may indeed be an important setting in which inequalities may be addressed. Similarly, there is suggestive evidence that housing change may positively affect physical and mental health, but the actual effects may be small.

In the case of transport, the strongest evidence derives from studies of injury prevention, but the wider health impacts of transport policies on inequalities remain to be elucidated further. Given the importance of access to healthcare in potentially helping to reduce health inequalities, it was notable that there is still only limited evidence of effects on health and no direct evidence of impacts on inequalities in health. Similarly, the systematic review evidence base in regards to the other social determinant domains is very limited particularly in terms of the effects of interventions on health inequalities, and in the case of the unemployment and welfare domain on general health, too.

We found no reviews on interventions relating to macroeconomic, cultural and environmental conditions (the outermost layer of the rainbow-figure 1). These conditions influence the standard of living achieved by different sections of the population, the prevailing level of income inequality, unemployment, job security and so on. Interventions within this category would therefore be aimed at altering the macroeconomic or cultural environment to reduce poverty and the wider adverse effects of inequality on society, including measures to ensure legal and human rights, "healthier" macroeconomic and labour market policies, the encouragement of cultural values promoting equal opportunities and environmental hazard control (including upholding international obligations and treaties in this field). ${ }^{51}$ This gap may be as a result of our focus on intervention studies and it may well be that the evidence base therefore needs to be widened to include reviews of comparative (non-intervention) studies such as those conducted within social epidemiology (such as that by Lynch et al ${ }^{52}$ on the association between income inequality and population health).

Clearly, education is the starkest example of an area in which there can be further development. The reviews that do exist either date from pre-2000 or relate to developing countries. We located no reviews relating to education and adult health outcomes published in this current decade concerning the situation in the high-income countries of the OECD. There are therefore unanswered questions, ripe for review, concerning the relationships between levels of education in a society and/or the nature of educational systems and health outcomes, and how these health outcomes differ by socioeconomic position.

Similarly, it was particularly difficult to identify appropriate reviews in the domain of "access to health and social care" as a social determinant of health. Despite extensive and rigorous searching, we only identified four systematic reviews that met our inclusion criteria. Moreover, the studies in the reviews do not represent the full range or intensity of potential intervention types in this domain. There is-for example, a clear need for reviews of the effects of nationwide changes in health systems to improve geographic, economic or cultural access for the population as a whole and for groups in greater need in particular.

In terms of the unemployment and welfare domain, there are still areas in need of further research, particularly in terms of the effects on health of welfare to work policies (eg, for lone parents, for the long-term unemployed, for young people), as well as the effects of interventions designed to prevent ill health among people out of work. Similarly, in the transport domain, the effects of policies to promote healthy transport (such as policies to promote walking) require further research. ${ }^{53}$ More studies are needed in terms of food policies (eg, the effects of the EU Common Agricultural Policy on food pricing and consumption); and in relation to water and sanitation interventions, the effects of water metering, which has been suggested may to lead to poorer families economising on water to the detriment of child health, is an important gap in the systematic review evidence.

\section{Limitations}

The main challenge was simply that there were too few systematic reviews conducted. It was also a challenge to locate the relevant systematic reviews that had been conducted. Searching for studies on the social determinants of health and/or health inequalities is difficult and time-consuming, and the searches can often suffer from a lack of sensitivity and a lack of specificity. ${ }^{54}$ However, to ensure the searches were as extensive as possible, our search strategies were piloted and revised. Furthermore, the searches were conducted by experienced specialist staff at the York Centre for Reviews and Dissemination. In addition, leading public health journals were hand searched and review authors were contacted. Despite this, as for any review of complex and difficult-to-define social 
interventions, it is not possible to be sure that all reviews have been located. ${ }^{55}$ However, there is confidence that the gaps identified, although perhaps surprising, are real. Another important issue to consider with umbrella reviews is the risk of study overlap between the included systematic reviews. However, in keeping with previous public health policy umbrella reviews, ${ }^{9}$ we found very little overlap-for example, in the work environment domain, there were no common studies. A more general limitation of public policy research is also relevant as a lot of the studies included in this umbrella review are from the USA, and there is evidence that the contextual determinants of health act differently in the USA than in Europe due in part to the different welfare systems in place. ${ }^{56}$ The findings of the USA studies may not therefore be easily transferrable to the European policy context.

\section{CONCLUSION}

It appears, then, that not only is the public health systematic review evidence base weak in terms of how to tackle the social determinants, but that there are specific areas that appear especially sparsely populated. These are sector-wide policies in education, the health system, food and agriculture, and more generally on the influence of macro-level policies on health inequalities. Although it is now a given that the effects of any interventions on inequalities should be assessed, the systematic review evidence base does not yet allow us to say with any confidence what the effects of interventions on reducing health inequalities are because differential impacts by socioeconomic position are rarely assessed. Nonetheless, one of the positive messages from this umbrella review is that there is a growing

\section{What is already known on this topic}

- The importance of the social determinants of health inequalities is well established.

- Therefore, there is increasing pressure to tackle these wider social determinants of health, through the implementation of appropriate interventions.

- However, there is a lack of evidence about what can actually be done to tackle the social determinants of health and health inequalities.

\section{What this study adds}

- This study synthesises recent systematic reviews on the effects on health and health inequalities of interventions aimed at influencing the social determinants of health.

- It thereby identifies what we already know in terms of the effects of interventions on health and health inequalities, and also where further work needs to be done.

- Evidence on the differential impacts of interventions by socioeconomic position is largely absent in the systematic review evidence base, although there is suggestive evidence that certain categories of intervention may impact positively on inequalities or on the health of specific disadvantaged groups, in particular, interventions in the fields of housing and the work environment. systematic review evidence base around housing and regeneration and a significant evidence base on the work environment suggesting that this is indeed a sector with significant responsibility for improving health and reducing inequalities. Given the few intervention studies that address inequalities, it is particularly important to assemble evidence on the mechanisms by which policies may affect health; this will help identify points at which to intervene and will provide a framework for the development of new research. ${ }^{51}$ For example, the results of systematic reviews that have evaluated the effects of interventions on the determinants of health (but which do not have health as an outcome) could also be examined and their findings extrapolated to tackling health inequalities. This is consistent with the WHO Commission on Social Determinants and the Measurement and Evidence Knowledge Network advice that as evidence comes in many shapes and forms, there is a need to get smarter about synthesising and appraising that evidence. ${ }^{8}$

Funding The work was supported by the Public Health Research Consortium. The Public Health Research Consortium is funded by the English Department of Health Policy Research Programme. The views expressed in the publication are those of the authors and not necessarily those of the $\mathrm{DH}$. Information about the wider programme of the PHRC is available from www.york.ac.uk/phrc. The funders had no involvement in the study design, execution or write-up. Other funders: Department of Health.

\section{Competing interests None.}

Contributors CB participated in the design of the study, collected, analysed and synthesised the data; led the writing of the article; and is a guarantor. MG assisted with data collection, analysis and synthesis and contributed to the writing of the article. AS participated in the design of the study, assisted in analysis and synthesis and contributed to the writing of the article. KW participated in data collection and contributed to the writing of the article. MW assisted in analysis and synthesis and contributed to the writing of the article. MP participated in the design of the study, assisted in analysis and synthesis and contributed to the writing of the article. All the named authors approved the final version.

Provenance and peer review Not commissioned; externally peer reviewed

\section{REFERENCES}

1. Graham H. Unequal lives: health and socioeconomic inequalities. Maidenhead: Open University Press, 2007

2. Acheson D. Independent inquiry into inequalities in health (the Acheson Report) London: HMSO, 1998.

3. Commission on Social Determinants of Health. Closing the gap in a generation: health equity through action on the social determinants of health. Geneva: World Health Organization, 2008.

4. Wanless D. Securing good health for the whole population: Final report. London: HM Treasury, 2004

5. Marmot M, Siegrist J, Theorell T, et al. Health and the psychosocial environment at work. In: Marmot M, Wilkinson R, eds. The social determinants of health. New York: Oxford University Press, 1999.

6. Barreto ML, Garcia AM, Bobak M, et al. JECH: new editorial directions. J Epidemiol Community Health 2009;61:1-2.

7. Marmot M. Fair Society, Healthy Lives: The Marmot Review. London: University College London, 2010.

8. World Health Organisation. Measurement and evidence knowledge network. 2008. http://www.who.int/social_determinants/knowledge_networks/measurement/ en/index.html (accessed Jan 2008)

9. Main C, Thomas S, Ogilvie D, et al. Populaiton tobacco control interventions and their effects on social inequalities in smoking: placing an equity lens on existing systematic reviews. BMC Public Health 2008;8:178.

10. Bialy L, Smith M, Bourke T, et al. The Cochrane Library and bronchiolitis: an umbrella review. Evid Base Child Health 2006;1:939-47.

11. Morrison D, Petticrew M, Thomson H. What are the most effective ways of improving population health through transport interventions? Evidence from systematic reviews J Epidemiol Community Health 2003;57:327-33.

12. Egan M, Tannahill C, Petticrew M, et al. Psychosocial risk factors in home and community settings and their associations with population health and health inequalities: a systematic meta-review. BMC Public Health 2008:8:239.

13. Higgins J, Green S, eds. Cochrane handbook for sytematic reviews of interventions Chichester: Wiley-Blackwell, 2008.

14. Dahlgren G, Whitehead M. European strategies for tackling social inequities in health: levelling up, Part 2. Copenhagen: WHO Regional Office for Europe, 2007.

15. Oliver S, Kavanagh J, Caird J, et al. Health promotion, inequalities and young people's health: a systematic review of research. London: London EPPI-Centre. Institute of Education, 2008. 
16. Howden-Chapman P, Matheson A, Crane J, et al. Effect of insulating existing houses on health inequality: cluster randomised study in the community. Br Med J 2007;334:460

17. Anderson LM, St Charles J, Fullilove MT, et al. Providing affordable family housing and reducing residential segregation by income-a systematic review. Am J Prev Med 2003:24:47-67.

18. Acevedo-Garcia D, Osypuk TL, Werbel RE, et al. Does housing mobility policy improve health? Housing Policy Debate 2004;15:49-98.

19. Chang JT, Morton SC, Rubenstein LZ, et al. Interventions for the prevention of falls in older adults: systematic review and meta-analysis of randomised clinical trials. Br Med J 2004;328:680.

20. McClure R, Turner C, Peel N, et al. Population-based interventions for the prevention of fall-related injuries in older people. Cochrane Database Syst Rev 2005;(1): CD004441.

21. Nilsen P. What makes community based injury prevention work? In search of evidence of effectiveness. Inj Prev 2004;10:268-74.

22. Thomson H, Petticrew M, Morrison D. Health effects of housing improvement: systematic review of intervention studies. Br Med J 2001;323:187-90.

23. Saegert S, Klitzman S, Freudenberg N, et al. Healthy housing: a structured review of published evaluations of US interventions to improve health by modifying housing in the US 1990-2001. Am J Public Health 2003;93:1471-7.

24. Hahn RA, Bilukha 0, Crosby A, et al. Firearms laws and the reduction of violence: a systematic review. Am J Prev Med 2005;28:40-71.

25. Thomson $\mathbf{H}$, Atkinson $\mathrm{R}$, Petticrew $\mathrm{M}$, et al. Do urban regeneration programmes improve public health and reduce health inequalities: a synthesis of the evidence from UK policy and practice (1980-2004). J Epidemiol Community Health 2006;60:108-15.

26. Aust B, Ducki A. Comprehensive health promotion interventions at the workplace: experiences with health circles in Germany. J Occup Health Psychol 2004; 9:258-70.

27. Egan M, Bambra C, Thomas S, et al. The psychosocial and health effects of workplace reorganisation. 1. A systematic review of organisational-level interventions that aim to increase employee control. J Epidemiol Community Health 2007;61:945-54.

28. Bambra C, Egan M, Thomas S, et al. The psychosocial and health effects of workplace reorganisation. 2. A systematic review of task restructuring interventions. J Epidemiol Community Health 2007:61:1028-37.

29. Bambra C, Whitehead M, Sowden A, et al. A hard day's night? The effects of compressed work week interventions on the health and wellbeing of shift workers: a systematic review. J Epidemiol Community Health 2008;62:764-77.

30. Bambra C, Whitehead M, Sowden A, et al. Shifting schedules: the health effects of reorganising shift work. Am J Prev Med 2008;34:427-34.

31. Egan M, Petticrew M, Ogilvie D, et al. "Profits before people"? A systematic review of the health and safety impacts of privatising public utilities and industries in developed countries. J Epidemiol Community Health 2007;61:862-70.

32. Rivara FP, Thompson DC. Prevention of falls in the construction industry: evidence for program effectiveness. Am J Prev Med 2000;18:23-6.

33. Shults R, Elder R, Sleet D, et al. Review of evidence regarding interventions to reduce alcohol impaired driving. Am J Prev Med 2001;23:66-88.

34. Ogilvie D, Egan M, Hamilton V, et al. Promoting walking and cycling as an alternative to using cars: a systematic review. Br Med J 2004;329:763-6.

35. Bunn F, Collier T, Frost $\mathrm{C}$, et al. Traffic calming for the prevention of road traffic injuries: systematic review and meta-analysis (review). Inj Prev 2003;9:200-4.
36. Egan M, Petticrew M, Ogilvie Da HV New roads and human health: a systematic review. Am J Public Health 2003;93:1463-71.

37. Pilkington $\mathbf{P}$, Kinra S. Effectiveness of speed cameras in preventing road traffic collisions and related casualties: systematic review. $\mathrm{Br}$ Med J 2005; 330:331-4

38. Anderson LM, Scrimshaw SC, Fullilove MT, et al. Culturally competent healthcare systems-a systematic review Am J Prev Med 2003;24:68-79.

39. Lewin SA, Dick J, Pond P, et al. Lay health workers in primary and community health care. Cochrane Database Syst Rev 2005:(1):CD04015.

40. Pignone M, DeWalt DA, Sheridan S, et al. Interventions to improve health outcomes for patients with low literacy: a systematic review. J Gen Intern Med 2005;20:185-92.

41. Gruen RI, Weeramanthri TS, Knight SE, et al. Specialist outreach clinics in primary care and rural hospital settings. Cochrane Database Syst Rev 2003. Issue 4. CD003798

42. Bartley M, Ferrie J, Montgomery S. Health and labour market disadvantage: unemployment, non-employment and job insecurity. In: Marmot M, Wilkinson R, eds. The social determinants of health. Oxford: Oxford University Press, 1999.

43. Crowther R, Marshall M, Bond G, et al. Helping people with severe mental illness to obtain work: systematic review. Br Med J 2001:322:204-8.

44. Bambra C, Whitehead M, Hamilton V. Does "welfare-to-work" work? A systematic review of the effectiveness of the UK's welfare-to-work programmes for people with a disability or chronic illness Soc Sci Med 2005:60:1905-18.

45. Adams J, White M, Moffatt $\mathrm{S}$, et al. A systematic review of the health, social and financial impacts of welfare rights advice delivered in healthcare settings. $B M C$ Public Health 2006:6:81.

46. Dahlgren G, Nordgren P, Whitehead M. Health impact assessment of the EU Common Agricultural Policy. Stockholm: Swedish National Institute of Public Health, 1996.

47. Wall J, Mhurchu C, Blakely T, et al. Effectiveness of monetary incentives in modifying dietary behavior: a review of randomized, controlled trials. Nutr Rev 2006;64:518-31.

48. Demos L, Kazda H, Cicuttini FM, et al. Water fluoridation, osteoporosis, fractures: recent developments. Aust Dent J 2001:46:80-7.

49. Millward L, Kelly M, Nutbeam D. Public health interventions research: the evidence. London: Health Development Agency, 2003.

50. Marmot M. Status syndrome: how your social standing directly affects your health London: Bloomsbury, 2005

51. Whitehead M. A typology of actions to tackle social inequalities in health J Epidemiol Community Health 2007;61:473-8.

52. Lynch J, Davey Smith G, Harper S, et al. Is income inequality a determinant of population health? Part 1. Milbank 0 2004:82:5-99.

53. McCarthy M. Transport and health. In: Marmot M, Wilkinson R, eds. Social determinants of health. Oxford: Oxford University Press, 2004.

54. Jackson $\mathbf{N}$, Waters $\mathrm{E}$. The challenges of systematically reviewing public health interventions. J Public Health (Oxf) 2004;26:303-7.

55. Ogilvie D, Hamilton V, Egan M, et al. Systematic reviews of health effects of socia interventions: 1. Finding the evidence: how far should you go? J Epidemiol Community Health 2005;59:804-8.

56. Chow CK, Lock K, Teo K, et al. Environmental and societal influences acting on cardiovascular risk factors and disease at a population level: a review. Int J Epidemiol 2009. [Epub ahead of print]. 